\title{
Introduction of Advanced Electron Microscopy In-situ Techniques in CAMMA
}

\section{Lichun ZHANG $^{1}$ and Mark Aindow ${ }^{2}$}

${ }^{1}$ UCUconn/Thermo Fisher Scientific Center for Advanced Microscopy and Materials Analysis, Storrs Mansfield, Connecticut, United States, ${ }^{2}$ University of Connecticut, Storrs, Connecticut, United States

Since April 2018, UConn/Thermo Fisher Scientific Center for Advanced Microscopy and Materials Analysis (CAMMA) was moved into the new innovation partnership building (IPB) in Uconn. With further integration and optimization, the facilities in the CAMMA are becoming more powerful technique in the field of materials characterization due to their increasing functionalities and capabilities in new IPB location. Fundamentals of some advanced in-situ techniques associated with these EM facilities will be introduced in this talk.

Two examples of in-situ MEMS heating experiments by using advanced CAMMA electron microscopy and microanalysis [1] was summarized:

1. In-situ MEMS Heating was performed on the as-cast Ti-44Al-8Nb-1.5Mn-1.0Cr-0.2B-0.2Y intermetallic alloy, and the morphological and chemical change from initial microstructure with $\mathrm{b} / \mathrm{a} / \mathrm{g}$ multi-phase were observed, as shown in Figure 1; (1) After heating at $600^{\circ} \mathrm{C}$ for as long as $40 \mathrm{mins}$, morphology and chemistry basically remain unchanged; (2) After continuous heating up to $975^{\circ} \mathrm{C}$, the $\mathrm{b}$ phase on grain boundary changed rapidly even after a few minutes; Several elements segregate, especially near the triple boundary; New precipitates formed at the a/g lamellar grain interior. (3) After heating $1200^{\circ} \mathrm{C}$ for $5 \mathrm{mins}$, new small grains of $\sim 100 \mathrm{~nm}$ in size appeared, all of the elements rapidly become evenly distributed; the evaporation of $\mathrm{Al} / \mathrm{Cr} / \mathrm{Mn}$ elements become severe.

2. In another work, we employed in-situ MEMS heating holder to investigate this abnormal crystallization of high-entropy TiZrHfCoCuNi metallic glass by high-resolution TEM imaging, as shown in Figure 2. (1) When it was heated to $450{ }^{\circ} \mathrm{C}$, some nano-scale clusters appearing in white contrast formed, and the EDS mapping indicated that there was some compositional fluctuation around these nano-scale clusters. (2) When it was further heated to $500{ }^{\circ} \mathrm{C}$, the nucleation of crystallites took place after a few minutes. Afterwards it was kept at $500{ }^{\circ} \mathrm{C}$ for $\sim 26 \mathrm{~min}$, some crystallites of $10 \mathrm{~nm} \sim 50 \mathrm{~nm}$ in size have formed with well-defined grain boundaries. In overall, the sample showed rapid nucleation but very slow grain growth during annealing at $500^{\circ} \mathrm{C}$. According to in-situ continuous video recording of the high-resolution lattice images, a preliminary structural model with lineup of squeezed octahedral units during crystallization is recommended. 

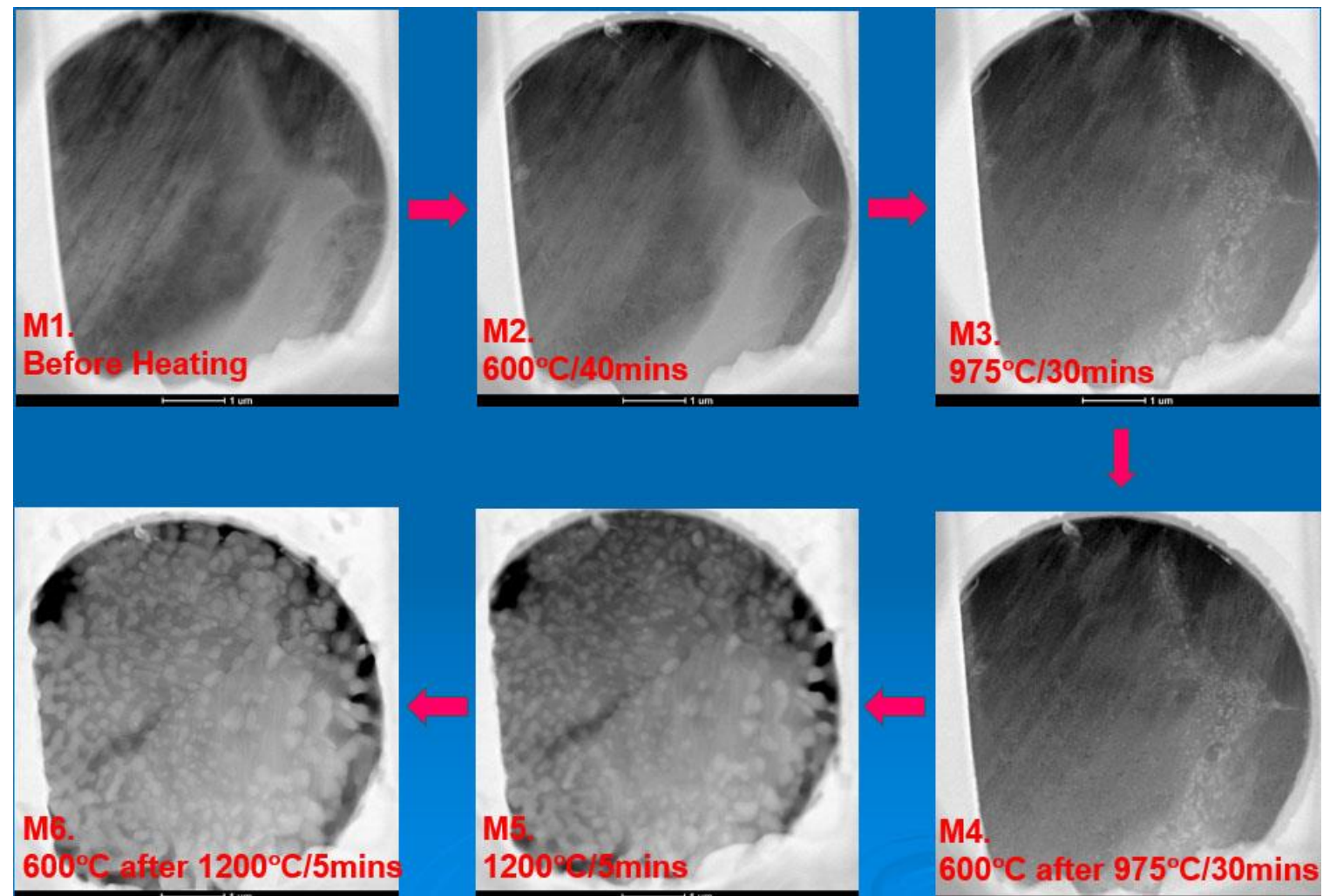

Figure 1. The morphological and chemical change during In-situ MEMS Heating on the as-cast Ti-44Al-8Nb$1.5 \mathrm{Mn}-1.0 \mathrm{Cr}-0.2 \mathrm{~B}-0.2 \mathrm{Y}$ intermetallic alloy
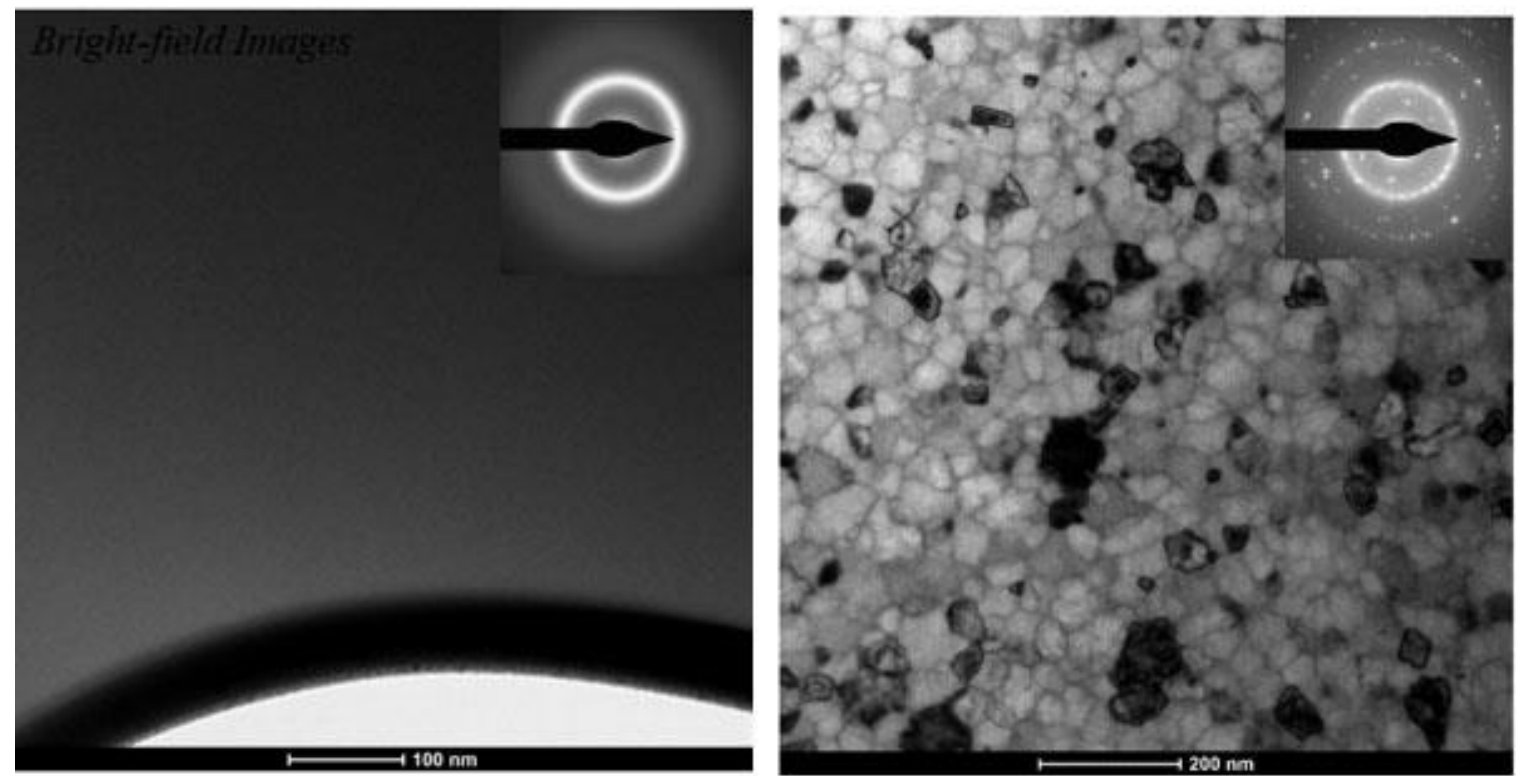

Figure 2. This abnormal crystallization of high-entropy TiZrHfCoCuNi metallic glass by in-situ observation duringMEMS heating: Left-initial amorphous; Right- After $500^{\circ} \mathrm{C} / 26$ minutes

\section{References}

[1] FIB Preparation of Samples for MEMS-based TEM Heating Experiments; By S Vijayan, JR Jinschek, S Kujawa, J Greiser and M Aindow. Microsc Microanal. 23: 708-716 (2017). 